\title{
A two year retrospective study of cytohistopathological correlation of cervical smear in a tertiary care hospital
}

\author{
Anilkumar Sirasagi ${ }^{1}$, Arpitha $\mathrm{K}^{2}$, Saara Neeha ${ }^{3}$, Pratima Manohar Pattar ${ }^{4}$ \\ ${ }^{1}$ Professor and Head, ${ }^{2}$ Senior Resident, ${ }^{4}$ Assistant Professor, Department of Pathology, ESIC Medical College \& \\ Hospital, Kalaburagi, Karnataka, India, ${ }^{3}$ Tutor, Department of Pathology, Raichur Institute of Medical Sciences, Raichur, \\ Karnataka, India
}

Background: Cervical cancer in women is the second most common cancer and the commonest cause of mortality in developing countries. The introduction of Pap smear test changed the scenario of cervical cancer with an intense drop in the incidence and mortality due to invasive cervical cancer. Aims and Objective: To evaluate the patterns of cervical smear cytology and to correlate the cervical smear diagnosis with histopathological diagnosis and to assess the efficacy of Pap smears in diagnosing cervical lesions. Materials and Methods: This two-year retrospective study (January 2018 to December 2019) was done in the department of Pathology in a tertiary care hospital. The sensitivity, specificity, positive predictive value, negative predictive value and accuracy were calculated considering histopathological diagnosis of cervical biopsy as the gold standard. Results: A total of 316 Pap smears were studied, out of which we selected 154 cases who also undergone biopsy or hysterectomy. Epithelial cell abnormalities (ECA) were found in 28 cases (18.2\%). Among this the most common ECA was Atypical squamous cells of undetermined significance (ASCUS) seen in 10 cases $(6.5 \%)$ followed by Low grade squamous intraepithelial lesion (LSIL) (5.2\%), High grade squamous intraepithelial lesion (HSIL) $(3.2 \%)$ and SCC of cervix (3.2\%). The overall correlation between cervical cytology and histopathology was found in 125 out of 154 cases (81.16\%). The sensitivity, specificity, positive predictive value, negative predictive value and accuracy of pap smear was $90.57 \%, 62.50 \%, 95.41 \%$, $43.47 \%$ and $87.66 \%$ respectively. Conclusion: Pap smear is a simple, safe, non-invasive and effective method for detection of lesions of the cervix and ECA. Hence, better awareness and periodical cytological screening programs can help in the early detection of malignant cervical lesions and thereby reducing the morbidity and mortality related to this malignancy.

Key words: Atypical squamous cells of undetermined significance (ASCUS); Carcinoma cervix; High grade squamous intraepithelial lesion (HSIL); Low grade squamous intraepithelial lesion (LSIL); Pap smears

\section{Access this article online}

Website:

http://nepjol.info/index.php/AJMS DOI: 10.3126/ajms.v12i8.36940

E-ISSN: 2091-0576

P-ISSN: 2467-9100

Copyright (c) 2021 Asian Journal of Medical Sciences

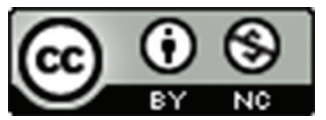

This work is licensed under a Creative Commons Attribution-NonCommercial 4.0 International License.

\section{INTRODUCTION}

Cervical cancer in women aged between 15-44 years is the second most common cancer and the commonest cause of mortality among women in developing countries. ${ }^{1}$

India, a developing country shows the trend of cervical cancer in higher magnitude. As per the World Cancer statistics, developing countries and those with limited resources attributes to more than $80 \%$ of all cervical cancer which in turn are attributable to lack of awareness and striving in running cytology based screening programs. ${ }^{2}$ An estimate of 122,844 women are diagnosed with cervical cancer every year in India and 67,477 women die from the disease. $^{3}$

Preventable nature of cervical cancer is due to its long pre invasive stage. However, robust approach like screening method in the form of Pap smear test if implemented can detect invasive cervical cancer in early stage, precancerous cervical intraepithelial neoplasia and hence suitable treatment can be instituted promptly. ${ }^{4}$ 
The introduction of Pap smear test changed the scenario of cervical cancer in worldwide with an intense drop in the newer cases and mortality due to cervical cancer which are invasive in nature. ${ }^{5}$ Though cervical biopsy an invasive technique remains a gold standard for detection of cervical lesions, Pap smear is a simple, safer, effective and non-invasive method. ${ }^{6,7}$

Aim of the study was to evaluate the patterns of cervical smear cytology and to correlate the cervical smear diagnosis with histopathological diagnosis and to know the accuracy of Pap smears, so as to assess the efficacy of Pap smears in diagnosing cervical lesions.

\section{MATERIALS AND METHODS}

This was a two year retrospective study conducted in the Department of Pathology, ESIC Medical College \& Hospital, Kalaburagi, from January 2018 to December 2019. After taking Institutional Ethics Committee permission (Approval No: ESICMC/GLB/IEC/16/2021), medical records data pertaining to demographic details, detailed clinical history including parity and complaints like discharge through vagina, post coital bleeding, post- menopausal bleeding, pain in lower abdomen, intermenstrual bleeding etc. were taken from hospital records who underwent Pap smear and cervical biopsy. Pregnant women, Unmarried women and women without sexual exposure were excluded from the study.

The Pap smears were taken with the Ayer's spatula on a clean glass slide and fixed instantly in ninety five percent ethanol and ether equal parts. Staining of the slides was performed by conventional Pap staining. Pap smears were reported as per the Bethesda System 2001 classification. Ten percent neutral buffered formalin solution was used to fix cervical biopsies or hysterectomy specimens and processed with final embedding in blocks prepared with paraffin and stained with haematoxylin and eosin (H \& E).

The histopathological findings were correlated with Pap smear findings and specificity, sensitivity, positive predictive value (PPV), negative predictive value (NPV) and accuracy were also calculated considering histopathological diagnosis of cervical biopsy as the gold standard. Data was collected in Microsoft Excel sheet and inferred by applying descriptive analysis using IBM SPSS Statistics for Windows, Version 22.0.

\section{RESULTS}

A total of 316 Pap smears were studied, out of which we selected 154 cases who were also undergone biopsy or hysterectomy during the period from January 2018 to
December 2019 retrospectively. Majority of the patients $(35 \%)$ were in age group of $41-50$ years and belong to para $2(42 \%)$ followed by para $3(25.6 \%)$. Most common complaint presented by patients was of whitish discharge per vaginum $(42 \%)$ and pain lower abdomen $(35.7 \%)$ followed by the other complaints like intermenstrual bleeding, menorrhagia, postcoital bleeding and postmenopausal bleeding in $15.2 \%, 3.5 \%, 3.2 \%$ and $0.4 \%$ cases respectively.

In the pap smear findings of 154 cases, the majority of cases $116(75.3 \%)$ were categorised as Negative for Intraepithelial lesion or malignancy (NILM). Epithelial cell abnormalities (ECA) were found in 28 cases $(18.2 \%)$. Among the ECA; Atypical squamous cells of undetermined significance (ASCUS) was most common and was seen in 10 cases $(6.5 \%)$ followed by low grade squamous intraepithelial lesion (LSIL) in 8 cases (5.2\%) (Figure 1), high grade squamous intraepithelial lesion (HSIL) in 5 cases $(3.2 \%)$ (Figure 2 ) and 5 cases $(3.2 \%)$ of squamous cell carcinoma were reported (Table 1).

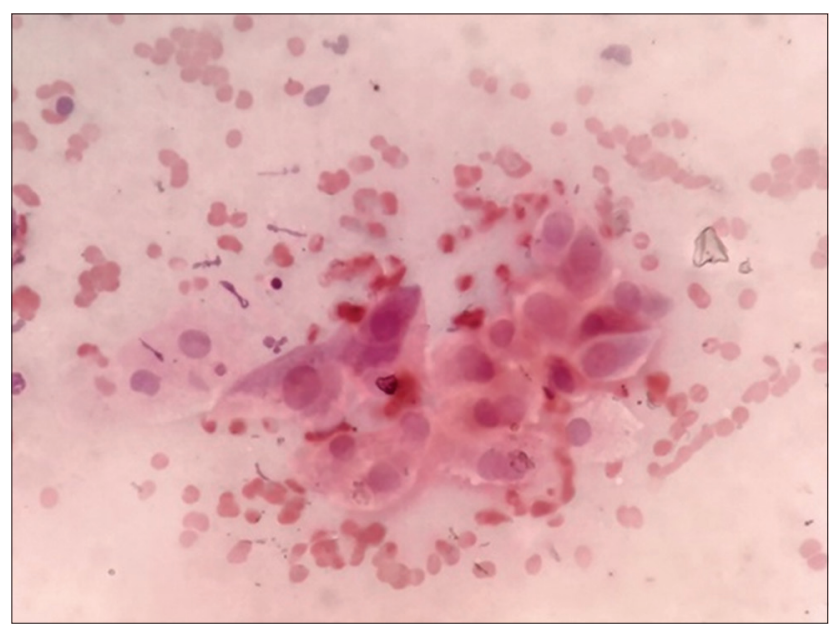

Figure 1: LSIL showing enlarged hyperchromatic nuclei with regular nuclear borders (Pap 40X)

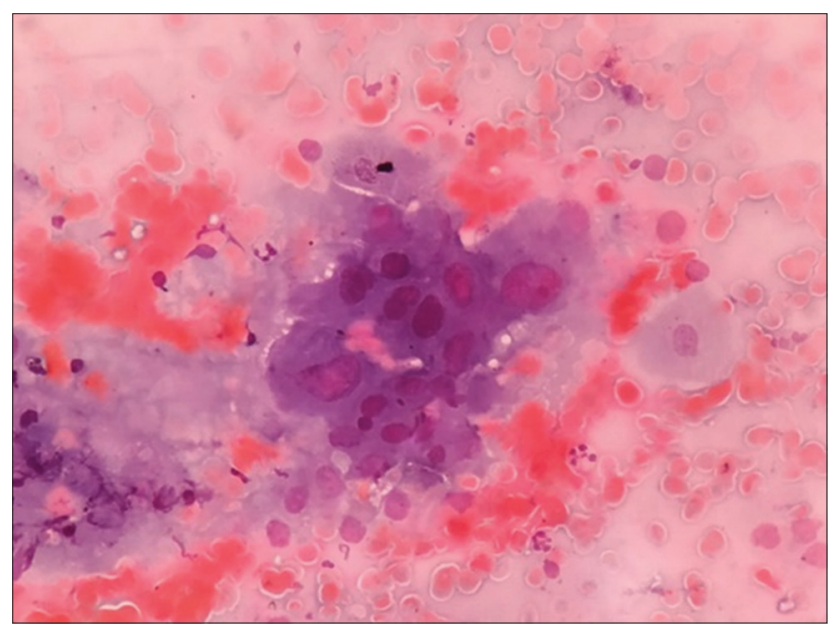

Figure 2: HSIL showing enlarged nuclei with irregular coarsely clumped chromatin and irregular nuclear borders (Pap 40X) 


\begin{tabular}{|c|c|c|c|c|c|c|c|}
\hline $\begin{array}{l}\text { HP } \\
\text { Pap }\end{array}$ & Cervicitis & CIN I & CIN II & CIN III & Carcinoma in situ & scc & Total \\
\hline NILM & 115 & 01 & - & - & - & - & $116(75.4 \%)$ \\
\hline ASCUS & 07 & 01 & 01 & 01 & - & - & $10(6.5 \%)$ \\
\hline LSIL & 03 & - & 01 & 01 & - & 03 & $08(5.2 \%)$ \\
\hline HSIL & 01 & 01 & - & - & 01 & 02 & $05(3.2 \%)$ \\
\hline SCC & - & 02 & - & - & - & 03 & $05(3.2 \%)$ \\
\hline Inadequate & 08 & - & - & - & - & 02 & $10(6.5 \%)$ \\
\hline Total & $134(87.0 \%)$ & $05(3.2 \%)$ & $02(1.3 \%)$ & $02(1.3 \%)$ & $01(0.7 \%)$ & $10(6.5 \%)$ & 154 \\
\hline
\end{tabular}

(HP- Histopathology, CIN-Cervical Intraepithelial Neoplasia, SCC- Squamous cell carcinoma, NILM- Negative for intraepithelial lesion/malignancy, ASCUS- Atypical squamous cells of undetermined significance, LSIL- Low grade squamous intraepithelial lesion, HSIL- High grade squamous intraepithelial lesion)

Table 2: Sensitivity and Specificity of Pap smear

\begin{tabular}{ll} 
Sensitivity & $90.57 \%$ \\
Specificity & $62.50 \%$ \\
Positive predictive value & $95.41 \%$ \\
Negative predictive value & $43.47 \%$ \\
Accuracy & $87.66 \%$ \\
\hline
\end{tabular}

With regard to histopathological diagnosis of cervical biopsies or hysterectomies, out of 154 cases $45.4 \%$ cases were diagnosed as chronic cervicitis, followed by chronic cervicitis with squamous metaplasia $(41.5 \%)$, Cervical intraepithelial neoplasia (CIN I) (3.2\%) (Figure 3a), CIN II $(1.3 \%)$ (Figure $3 \mathrm{~b}$ ) and CIN III (1.3\%). Squamous cell carcinoma was diagnosed in 10 cases $(6.5 \%)$ (Table 1$)$.

In our study the sensitivity, specificity, PPV, NPV and accuracy of pap smear was $90.57 \%, 62.50 \%, 95.41 \%$, $43.47 \%$ and $87.66 \%$ respectively (Table 2 ). The overall correlation between cervical cytology and histopathology was found in 125 out of 154 cases $(81.16 \%)$, thereby the pap smears have an important role in screening different types of cervical lesions.

\section{DISCUSSION}

Gynaecological malignancy in the form of cervical cancer is an ideal malignancy for screening. Since it has extended premalignant latent phase, Pap smear test as a screening method will be an effective way to detect early and prevent the progress of cervical cancer. However, awareness of Pap smear test within the community settings is very low. ${ }^{8}$

The present study included 154 pap smear cases who also undergone biopsy or hysterectomy with most patients $(35 \%)$ in the age group of $41-50 \mathrm{yrs}$ and belong to para $2(42 \%)$ followed by para $3(25.6 \%)$. It has accordance with Sachan et al., ${ }^{8}$ and Parija et al. ${ }^{9}$

The maximum number of patients presented with complaints of whitish discharge per vaginum (42\%) and pain lower abdomen (35\%) correlates with the study conducted by Bamanikar et al., ${ }^{10}$ Atla et al., ${ }^{11}$ and Bindroo et al. ${ }^{12}$

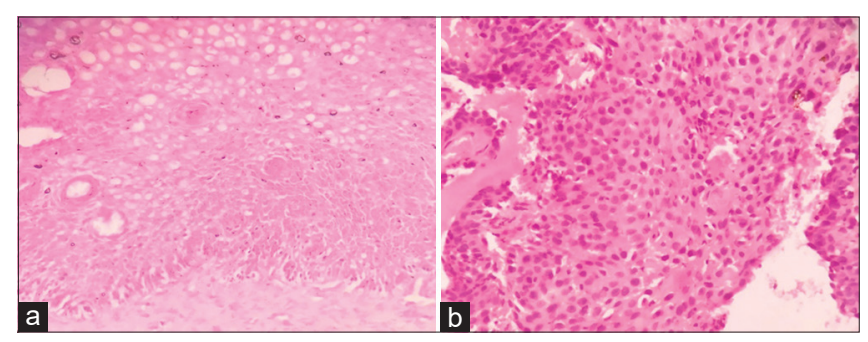

Figure 3: (a) CIN I: Increased nuclear density and variable nuclear hyperchromasia in upper epithelial layer (H\&E 40X). (b) CIN II: Cytological atypia in lower two thirds of epithelium with high N/C ratio and irregular nuclear membrane contour (H\&E 40X)

In our study out of 116 cases of NILM, 99\% of cases correlated on histopathology which corroborated with the studies done by Atla et al., ${ }^{11}$ and Bindroo et al. ${ }^{12}$ The incidence of Epithelial cell abnormality (ECA) was seen in $18.1 \%$ which correlated with Patil et al. ${ }^{13}$ But this incidence was higher than the study conducted by Malpani et al., ${ }^{14}$ this may be because we had small sample size.

Regardless in the level of expertise or years of training, variability with regards to interobserver and intraobserver reporting is high and is well documented in the literature. At times diagnostic challenges due to variations corroborating to hormone replacement therapy and perimenopausal changes and may lead to over diagnosis of ASCUS especially in elderly women. Reluctance to diagnose LSIL in women during peri-menopausal and postmenopausal period may also lead to more interpretations of ASCUS. ${ }^{11}$

In our study out of 10 cases of ASCUS on cytology, $30 \%$ cases correlated on histopathology while $70 \%$ cases were diagnosed as cervicitis with or without metaplasia. This discrepancy of pap smear on histopathology can be attributed to the fact that those cases had perimenopausal changes like cervical erosions or ulcers, which shows inflammatory atypia and these cells on cytology may be considered as atypical squamous cells.

Out of 8 cases of LSIL, 2 cases showed CIN, 3 cases showed cervicitis and 3 cases showed invasive cancer. Out 
Table 3: Comparison of pap smear values with other studies

\begin{tabular}{lccccc}
\hline Study & Sensitivity & Specificity & PPV & NPV & Accuracy \\
\hline Bamanikar et al $^{10}$ & 89.47 & 88.70 & 82.92 & - & - \\
Atla et al $^{11}$ & 94.11 & 64.28 & 82.75 & 85 & 78.2 \\
Bindroo et al $^{12}$ & 75.24 & 97.98 & 96.20 & 85.38 & 88.80 \\
Patil et al & 77.7 & 84.2 & 70.0 & 88.8 & 82.1 \\
Malpani et al & 86.61 & 73.33 & 96.49 & 39.29 & 85.21 \\
Present study & 90.57 & 62.50 & 95.41 & 43.47 & 87.66 \\
\hline (PPV- Positive predictive value, NPV- Negative predictive value) & & & &
\end{tabular}

of 5 cases, 4 cases of HSIL correlated on histopathology, but 1 case showed chronic cervicitis with metaplasia. These false negative results in cytohistologic comparison may be because of sampling error and artifacts during preparation like inadequate fixations, drying artifacts, background materials and thick smears. Though false negative rates are usually misjudged when using follow up controls, our value observation against immediate histologic 'gold-standard' reflects an effective screening program for cervical cancer. ${ }^{13}$

In our study, the overall sensitivity, specificity, PPV, NPV and accuracy of pap smear was $90.57 \%, 62.50 \%, 95.41 \%$, $43.47 \%$ and $87.66 \%$ respectively. These values were comparable to Bamanikar et al., ${ }^{10}$ Atla et al., ${ }^{11}$ and Malpani et $\mathrm{al}^{14}$ (Table-3). This study shows a good correlation between cervical cytology and histopathology.

\section{CONCLUSION}

Pap smear is a simple, safer, non-invasive, and effective method for detection of lesions of the cervix and ECA. But the accomplishment of screening is based on adequate sample collection and correct interpretation. Therefore better awareness, periodical cytological screening programs along with the use of thin-prep pap liquid based cytology technique, HPV and DNA testing can reduce inadequate sampling errors and help in early detection of cervical cancer.

\section{ACKNOWLEDGEMENT}

The authors take this opportunity to thank Department of Obstetrics and Gynaecology and all the technical staff, Department of Pathology for their whole hearted support for this study.

\section{REFERENCES}

1. Sreedevi A, Javed R and Dinesh A. Epidemiology of cervical cancer with special focus on India. International Journal of Women's Health. 2015:7 405-414.

https://doi.org/10.2147//JWH.S50001
2. Ferlay J, Soerjomataram I, Dikshit R, Eser S, Mathers C, Rebelo $\mathrm{M}$, et al. Cancer incidence and mortality worldwide: Sources, methods and major patterns in GLOBOCAN 2012. Int J Cancer. 2015;136: E359-E386.

https://doi.org/10.1002/ijc.29210

3. Arbyn M, Weiderpass E, Bruni L, Silvia de Sanjosé, Saraiya M, Ferlay J, et al. Estimates of incidence and mortality of cervical cancer in 2018: a worldwide analysis. Lancet Glob Health. 2020; 8: e191-e203.

https://doi.org/10.1016/S2214-109X(19)30482-6

4. Bal MS, Goyal R, Suri AK and Mohi MK. Detection of abnormal cervical cytology in papanicolaou smears. J Cytol. 2012;29: 45-47.

https://doi.org/10.4103/0970-9371.93222

5. Alakananda, Sarma $U$ and Biswas I. Histopathological Correlation with Cervical Cytology. IOSR Journal of Dental and Medical Sciences. 2016;15(11): 53-58.

https://doi.org/10.9790/0853-1511085358

6. Shaw PA. The History of Cervical Screening I: The Pap Test. J Soc Obstet Gynaecol Can. 2000;22: 110-114. https://doi.org/10.1016/S0849-5831(16)31416-1

7. Mainali N, Homagai N, Nepal N and Choudhary P. A correlation study of cervical cytology on Pap smear with cervical biopsy in a tertiary hospital of Eastern Nepal. Journal of Pathology of Nepal. 2018; 8: 1389-1392.

https://doi.org/10.3126/jpn.v8i2.20993

8. Sachan PL, Singh M, Patel ML and Sachan R. A study on cervical cancer screening using pap smear test and clinical correlation. Asia Pac J Oncol Nurs. 2018; 5:337-341.

https://doi.org/10.4103/apjon.apjon_15_18

9. Parija J and Mohapatra J. Clinical, cytological and histopathological correlation in lesions of uterine cervix. J Evolution Med Dent. Sci. 2017;6(64):4652-4655. https://doi.org/10.14260/Jemds/2017/1006

10. Bamanikar SA, Baravkar D, Chandanwale S, Dharwadkar A and Paranjape S. Study of cervical cytology and its correlation with clinical and histopathological findings. Clin Cancer Investig J. 2016; 5:403-408.

https://doi.org/10.4103/2278-0513.197869

11. Atla BL, Uma P, Shamili M and Satish Kumar S. Cytological patterns of cervical pap smears with histopathological correlation. Int J Res Med Sci. 2015;3(8):1911-1916. https://doi.org/10.18203/2320-6012.jirms20150300

12. Bindroo S, Garg M and Gitika. Correlation of cervical Pap smear with histopathological diagnosis in cervical lesions: a 2 years retrospective study. International Journal of Contemporary Medical Research. 2019;6(7): G17-G20.

https://doi.org/10.21276/ijcmr.2019.6.7.30

13. Patil PR and Jibhkate SN. Cytohistopathological correlation of Papanicolaou smears: a hospital based study. Int J Reprod 
Contracept Obstet Gynecol. 2016;5(6):1695-1699.

https://doi.org/10.18203/2320-1770.jjrcog20161424

14. Malpani G, Agrawal P, Varma AV, Khandelwal N and Tignath G. Cervical Pap smear study and detection of abnormal epithelial lesions and determination of its accuracy by cytohistological correlation in patients of tertiary care teaching hospital in central India. Int J Reprod Contracept Obstet Gynecol. 2016;5(7):2312-2316.

https://doi.org/10.18203/2320-1770.ijrcog20162118

AS- Concept and design of the study; prepared first draft of manuscript; AK- Statistically analysed and interpreted, preparation of manuscript and revision of the manuscript; SN- Concept, coordination, review of literature and manuscript preparation; PM- Concept and design of the study; Statistically analysed and interpreted, preparation of manuscript and revision of the manuscript.

\section{Work attributed to:}

ESIC Medical College \& Hospital, Kalaburagi, Karnataka, India.

Orcid ID:

Dr. Anilkumar Sirasagi- io https://orcid.org/0000-0002-9144-7953

Dr. Arpitha K- iD https://orcid.org/0000-0002-8075-8465

Dr. Saara Neeha- io https://orcid.org/0000-0002-3205-3129

Dr. Pratima Manohar Pattar- (1) https://orcid.org/0000-0002-4183-3311

Source of Funding: None, Conflict of Interest: None. 